\title{
ANÁLISE DAS LEGISLAÇÕES SOBRE OS PERCENTUAIS MÍNIMOS DAS ÁREAS VERDES DOS MUNICÍPIOS DA BACIA DO SOROCABA MÉDIO TIETÊ ESTADO DE SÃO PAULO
}

\author{
Daniela Gerdenits ${ }^{1}$, Elzo Savella ${ }^{2}$, Maurício Tavares da Mota ${ }^{3}$
}

\section{RESUMO}

A rápida urbanização degradou intensamente as cidades, atingindo também os espaços destinados às áreas verdes, as quais carecem de determinações quanto suas dimensões e funções. Neste contexto, o artigo tem como objetivo promover o debate sobre as definições, funções e tamanho das áreas verdes, estabelecidas nas legislações, principalmente municipais, incluindo plano diretor e lei de uso e parcelamento de solo dos municípios que abrangem a Bacia do Sorocaba Médio Tietê. A pesquisa baseou-se no levantamento de literatura relacionada e no estudo dos respectivos planos diretores e legislação de uso e de parcelamento de solo dos municípios da Bacia do Sorocaba Médio Tietê. Os resultados encontrados mostraram que os percentuais dos parcelamentos de solo destinados às áreas verdes variam muito. As áreas verdes, dada suas importâncias social, ambiental e de saúde pública deveriam ter seu percentual definido através de um instrumento participativo, tal como um plano diretor. Foi avaliado qual percentual de municípios definiram seus percentuais por meio de leis ordinárias ou complementares, que podem ser aprovadas ou modificadas sem mecanismos participativos.

Palavras-chave: áreas verdes, parcelamento do solo, plano diretor, urbanização, Bacia Sorocaba Médio Tietê.

\section{ABSTRACT}

The rapidly urbanizing cities heavily degraded, affecting also the spaces destined to green areas, which require determinations as their size and functions. In this context, the paper aims to promote debate on the definitions, functions and size of green areas, established in legislation, especially municipal, including master plan and law of land use and subdivision of the municipalities that comprise the Middle Tietê Basin Sorocaba. The research was based on the survey of related literature, and study of their master plans and rules of use and subdivision of land in the municipalities of the Middle Tietê Basin Sorocaba. The results showed that the percentage of parcels of land destined to green areas vary greatly. The green areas, given their social, environmental and public health should have their percentage defined through a participatory tool as a master plan. However, among the cities surveyed, $61.77 \%$ of their percentages set by laws common or complementary, which may be adopted or modified without participatory mechanisms. Only 32,25\% of them approved by their percentage of their master plans, and can only be changed through participatory ritual.

Key-words: green areas, land subdivision, master plan, urbanization, Bacia Sorocaba Médio Tietê.

\footnotetext{
${ }^{1}$ Bióloga, Ufscar-Sorocaba, Mestranda em Sustentabilidade na Gestão Ambiental, Sorocaba-SP, danigerdenits@yahoo.com.br;

${ }^{2}$ Licenciado em História, Ufscar-Sorocaba, Mestrando em Sustentabilidade na Gestão Ambiental, Sorocaba-SP, savella@globo.com;

${ }^{3}$ Biólogo. Ufscar-Sorocaba, Mestrando em Sustentabilidade na Gestão Ambiental, Sorocaba-SP, mauriciotavaresmota@gmail.com.

4 recebido em 28.05.2012 e aceito para publicação em 05.12.2013
} 
A rápida urbanização degradaram intensamente os espaços verdes presentes nas cidades que, em sua maciça maioria, não estavam preparadas para estruturar a nova demanda populacional em seus espaços, adequando-a a suas limitações. Como consequência, a ocupação desordenada do solo reduziu, não somente a qualidade de vida dos moradores, mas para muitos deles, inviabilizou o oferecimento de condições mínimas de sobrevivência, dentre elas, dos serviços municipais de saúde, educação e emprego. Dentro deste contexto, a política de desenvolvimento urbano, responsabilidade do município, tem por objetivo planejar e ordenar o desenvolvimento das funções sociais da cidade e garantir o bem estar de seus habitantes (Constituição Federal - art.182, 1988 apud ARFELLI, 2004).

“O plano diretor, obrigatório para as cidades com mais de vinte mil habitantes e para todos os municípios do Estado de São Paulo, foi idealizado como instrumento básico da política de desenvolvimento e de expansão urbana” (ARFELLI, 2004. p. 2). Além disso, como complemento, a Lei Federal $n^{\circ} 6.766$ de 1979 disciplina o parcelamento do solo urbano, na tentativa de garantir a regular e saudável ocupação urbana, não somente ligada a população, mas também ao meio ambiente (ARFELLI, 2004). De acordo com Pinto (2001), o plano diretor tem por finalidade evitar possíveis abusos, por parte do Poder Público, do direito de propriedade, buscandose a garantia, junto ao município, da regulação do mercado imobiliário a favor do interesse público.

As restrições urbanísticas objetivam o melhoramento das condições de vida coletiva, sob os aspectos físico, social e ambiental, principalmente devido à influência direta de um loteamento, gerando efeitos positivos e negativos difusos sobre a população fixa ou visitante em uma cidade. Neste contexto, as áreas verdes, que são espaços destinados a conservação do meio ambiente e lazer da população, exercem funções fundamentais da paisagem urbana, no cenário da ordenação urbanística. Trata-se de um componente de equilíbrio do meio ambiente urbano e de lazer. A boa apresentação dessa paisagem tem direta influência no meio, gerando efeitos sobre todos que dela se utilizam, proporcionando condições de uma sadia qualidade de vida (ARFELLI, 2004).

Segundo Arfelli (2004), não se pode confundir áreas verdes com as áreas non aedificandi, embora ambas tenham as funções de defesa de recuperação do meio ambiente, têm sua vocação voltada para o lazer. As áreas verdes e as de lazer (recreio) devem, por força de lei, ser exigidas pela municipalidade como requisito mínimo dos loteamentos e desmembramentos. O autor classifica as áreas verdes como típicas ou mistas. A primeira permite atividades de mínimo impacto, pois compreendem um contíguo de vegetação exuberante. Já a segunda, não há predominância da cobertura vegetal, admitindo a intervenção para implantação de equipamentos comunitários destinados ao lazer e recreação.

As áreas verdes urbanas têm influência positiva no meio e para a comunidade ao seu redor, que desempenha uma série de funções, tais como:

\section{- $\quad$ A função ecológica está ligada a existência} da vegetação, a permeabilidade do solo, a visita de animais que interagem com os componentes da área, entre outros fatores, que contribuiem nas melhorias no clima da cidade e na qualidade do ar, da água e do solo; 
- A função social está relacionada às diversas opções de lazer que essas áreas oferecem à comunidade ao redor.

- $\quad$ A função estética refere-se à diversificação da paisagem em meio às obras urbanas, gerando, além de beleza, a sensação de estar mais próximo da natureza em meio à uma cidade repleta de edificações.

- A função educativa está ligada com as diversas atividades as quais podem ser aplicadas em projetos educacionais fora do ambiente escolar, além de programas de educação ambiental.

- $\quad$ A função psicológica é contemplada com a possibilidade das pessoas ativarem seus cinco sentidos, quando entram em contato com os elementos naturais dessas áreas, contribuindo com a qualidade de vida. Este aspecto está relacionado com a prática do lazer e da recreação nessas áreas (LIMA et al., 1994; HENKE-OLIVEIRA, 1996; NUCCI, 1999; LOBODA; DE ANGELIS, 2005; MANTOVI, 2006; GUZZO, 2011);

- $\quad$ A função de saúde: diminuir a incidência de doenças respiratórias (LIMA et al., 1994).

A importância das áreas verdes está, dentre outros fatores, nas modulagens ambiental e social das cidades, agregando um complexo de elementos naturais e materiais voltados ao lazer e a recreação da população, além de amenizar a paisagem comumente edificada (RANGEL; RIBEIRO, 2010). A valorização e a proteção de áreas verdes, principalmente nas cidades grandes, deveriam ser prioridades em qualquer plano diretor, tendo como base a elaboração de projetos que contemplem programas de manejo, exigindo um detalhado planejamento para que essas áreas não se tornem problemas para a cidade, sendo eventualmente abandonadas ou ocupadas irregularmente. Esse planejamento deve contemplar a densidade populacional, faixa etária predominante e potencial de cada área do bairro, além da arborização, que precisa respeitar as necessidades biológicas das espécies e sua convivência junto ao perímetro urbano. Todas essas informações devem compor um documento que poderá representar materialmente um Sistema Municipal de Áreas Verdes (MANTOVI, 2006).

Neste contexto, este trabalho tem como objetivo promover o debate sobre as definições, funções e tamanho das áreas verdes estabelecidas nas legislações, entre outras, as municipais, incluindo plano diretor e lei de uso e de parcelamento de solo dos municípios que abrangem a Bacia do Sorocaba Médio Tietê.

\section{MATERIAIS E MÉTODOS}

A pesquisa baseou-se no levantamento de literatura relacionada no estudo dos respectivos planos diretores e legislação de uso e de parcelamento de solo dos municípios da Bacia do Sorocaba Médio Tietê (Figura 1).

Para tanto, foram estudados os trinta e quatro municípios dessa Bacia Hidrográfica e analisados os documentos referidos anteriormente, o que gerou a Tabela (1) com as seguintes informações: município, Lei, número da população pelo IBGE, percentual de área de lazer, área institucional, APP (área de proteção permanente), declividade do terreno, densidade populacional e mecanismo de conectividade.

As informações referentes à população foram obtidas no sítio do Instituto Brasileiro de Geografia e Estatística - IBGE, referentes ao senso realizado em 2010. Os trinta e quatro municípios , estão todos inseridos na Unidade de Gerenciamento de Recursos Hídricos do Estado de São Paulo 10 Daniela Gerdenits et al. 
(UGRHI-10). Esta divisão foi estabelecida pela Lei Estadual $n^{0} 7.663$, de 30 de dezembro de 1991, a qual estabelece normas de orientação à Política Estadual de Recursos Hídricos e ao agrupamento dos municípios em suas respectivas bacias, que obedecem critérios de interesses comuns (SÃO PAULO, 1991).

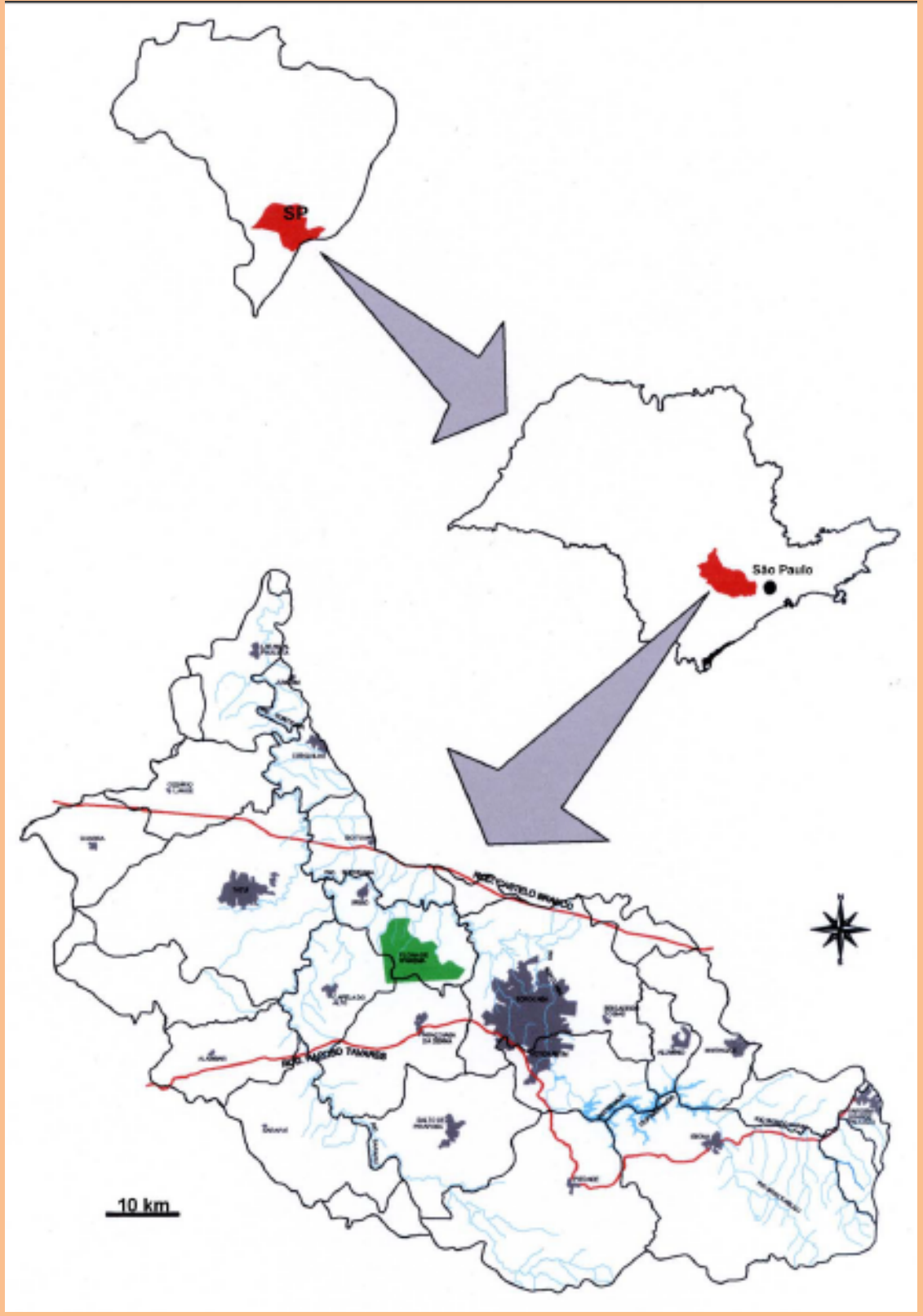

Figura 1: Bacia do Rio Sorocaba e Médio Tietê no Estado de São Paulo e Brasil (FÁVERO, 2007).

As informações de cada município foram obtidas por meio de legislações municipais específicas de parcelamento de solo e de planos diretores, por meio de pesquisa na rede mundial de computadores, em sítios específicos das respectivas prefeituras e câmaras municipais, quando disponíveis para consulta, e quando não, por contato telefônico com os setores responsáveis pela aprovação dos projetos de parcelamento de solo das prefeituras e solicitada cópia da legislação local que regulamenta o parcelamento de solo. 
Após o levantamento das informações acima,

importância para os municípios.

procedeu-se a análise das áreas verdes e sua

\section{RESULTADOS E DISCUSSÃO}

Os resultados encontrados na Tabela 1 mostram que os percentuais dos parcelamentos de solo destinados às áreas verdes variam muito. Entretanto, há predomínio da adoção do percentual de $10 \%$ da gleba para tais fins, com incidência em 15 (44,12\%) dos municípios, seguidos pelo percentual de $20 \%$ de áreas verdes em outros 7 (20,59\%). Cinco (14,71\%) dos municípios, embora tenham Plano Diretor, não possuem um percentual definido em Lei Municipal sobre as áreas verdes. Dois deles apresentaram números variáveis, sendo eles Votorantim, o qual indica um valor entre 7,5 e $10 \%$ de acordo com as características do parcelamento do solo, e Salto de Pirapora, que apresenta variação entre 12 e 20\%. Ocorreram, ainda, casos em que o percentual indicado por legislação municipal foi único, sem recorrência em nenhum outro município da Bacia como é o caso de Boituva, que indica o percentual de 5\% destinado às áreas verdes. Sorocaba é o único da bacia com o valor de $12 \%$ e Cesário Lange de $15 \%$.

Tabela 1: Variação de percentuais de áreas verdes adotados para parcelamentos de solo pelos municípios da UGRHI-10.

\section{Municípios}

Boituva

Alambari, Alumínio, Araçoiaba da Serra, Botucatu, Cerquilho, Itu, Laranjal Paulista, Piedade, Porangaba, Porto Feliz, Quadra, São Roque, Tatuí, Torre de Pedra e Vargem Grande Paulista

Sorocaba

Anhembi, Cesário Lange e Mairinque

Cabreúva, Capela do Alto, Conchas, Jumirim, Pereiras, Salto e Tietê

Salto de Pirapora

Votorantim

Araçariguama, Bofete, Iperó, Sarapuí e Ibiúna

\section{Área Verde (\%)}

5
12

15

20

12 a $20 \%$

7,5 a $10 \%$

não cita (Lei Federal) 
Em geral, os municípios que não citam o valor em legislação municipal, quando indagados, via telefone, sobre o assunto admitem a adoção das regras impostas pela Lei Federal $n^{0}$ 6.766/1979, definidas pelo parágrafo primeiro do artigo $4^{\circ}$, onde o percentual mínimo deveria ser de $35 \%$ da gleba destinada ao sistema viário, áreas verdes e institucionais, entretanto, este parágrafo foi alterado pela Lei Federal $n^{0}$ 9.785/1999 que deixou a cargo do município a definição do percentual de área verde e institucional dos loteamentos e que devem levar em consideração a proporcionalidade com a densidade populacional do loteamento.
É evidente a falta de um consenso sobre o valor adotado pelos municípios da bacia. Apenas quatro deles (Anhembi, Botucatu, Mairinque e Pereiras), na Tabela 2, consideram a densidade populacional para cálculo de suas áreas verdes, necessária segundo alterações na legislação federal. Também foram somente quatro (Anhembi, Cabreúva, Iperó e Votorantim), na Tabela 3, os que utilizaram meios legais com possibilidade de conectividade entre as áreas verdes, fundamental para atenuar os efeitos danosos da fragmentação dos ambientes naturais.

Tabela 2: Municípios que consideram a densidade populacional para seleção das áreas verdes.

\begin{tabular}{lc}
\hline Municípios & Considera \\
& Densidade \\
& populacional \\
\hline
\end{tabular}

Alambari, Alumínio, Boituva, Cabreúva, Capela do Alto, Cerquilho, Cesário Lange, Conchas, Ibiúna, Iperó, Itu, Jumirim, Piedade, Porangaba, Porto Feliz, Salto, Salto de Pirapora, São Roque, Sorocaba, Laranjal Paulista, Tatuí, Torre de Pedra, Vargem Grande Paulista, não Votorantim, Araçariguama, Bofete, Quadra e Sarapuí

Tabela 3: Municípios que adotam mecanismos de conectividade entre outros fragmentos já existentes, mesmo que fora da gleba que se pretende parcelar o solo.

\title{
Municípios
}

\section{Mecanismo \\ Conectividade}

\begin{abstract}
Alambari, Alumínio, Araçoiaba da Serra, Boituva, Botucatu, Cerquilho, Cesário Lange, Conchas, Ibiúna, Itu, Jumirim, Mairinque, Pereiras, Piedade, Porangaba, Porto Feliz, Salto, Salto de Pirapora, São Roque, Sorocaba, Tatuí, Tietê, Torre de Pedra, Vargem Grande Paulista, Araçariguama, Bofete, Laranjal Paulista, Quadra e Sarapuí e Capela do Alto
\end{abstract}

Não Cita

$\operatorname{sim}$ 
Apenas sete municípios (Tabela 4) apresentaram seus percentuais de áreas verdes definidos em Plano Diretor, fato fundamental, pois os Planos Diretores são ferramentas participativas e permitem, inclusive, a opinião popular na definição de suas diretrizes. Seis municípios (Tabela 4), embora disponham de planos diretores, não fazem referência aos percentuais de áreas verdes nesse documento; onze têm seus valores definidos por lei ordinária; seis por meio de leis complementares e nos demais municípios não foram detectadas legislações sobre o tema (Tabela 4).

Tabela 4: Instrumentos legais pelos quais os municípios definem seus percentuais de áreas verdes.

Municípios

Cesário Lange, Torre de Pedra, Araçoiaba da Serra, Boituva, Cabreúva, Itu e Jumirim

Bofete e Sarapuí

Alambari, Alumínio, Botucatu, Capela do Alto, Cerquilho, Conchas, Laranjal Paulista, Pereiras, Piedade, Porangaba, Quadra, Tatuí, Tietê e Vargem Grande Paulista

Anhembi, Araçariguama, Ibiúna, Iperó, Mairinque, Porto Feliz, Salto, Salto de Pirapora, São Roque, Sorocaba e Votorantim

\section{Lei}

não citam

Ordinária parcelamento

Plano diretor

Não foi observada relação entre o número de habitantes de cada município e a existência de normas legais sobre o objeto de estudo.

Com relação às áreas de preservação permanente, como parte integrante das áreas verdes dos loteamentos, Arfelli (2004), cita que o Instituto Brasileiro do Meio Ambiente e dos Recursos Naturais Renováveis (IBAMA) e a Secretaria do Meio Ambiente do Estado de São Paulo (SMA), pela Resolução Conjunta $n^{0}$ 02, de12 de maio de
1994 (BRASIL, 1994), estabelece a possibilidade das áreas verdes incluírem as áreas de preservação permanente (APP). Este fato foi objeto de pesquisa, descrito na Tabela 5, sendo observado que vinte e dois (64,71\%) municípios não citam se é possível a inclusão de APP, ou seja, não é claro esse item na legislação municipal; seis $(17,65 \%)$ deles não permitem a inclusão dessas áreas; quatro $(11,76 \%)$ aprovam essa situação e dois (5,88\%) concedem até certo percentual da área verde. 
Tabela 5: Modo como os municípios definem a inclusão de áreas de preservação permanente - APP como parte integrante das áreas verdes.

\section{Municípios}

\section{Inclui APP}

Alumínio, Anhembi, Cerquilho, Pereiras, Torre de Pedra e Araçoiaba da Serra

não

Alambari, Araçariguama, Boituva, Bofete, Botucatu, Capela do Alto, Cesário Lange, Conchas, Ibiúna, Iperó, Itu, Jumirim, Laranjal Paulista, Mairinque, Piedade,

Porangaba, Porto Feliz, Quadra, Salto, São Roque, Sarapuí e Vargem Grande Paulista

não cita

Salto de Pirapora, Sorocaba, Tatuí e Tietê

$\operatorname{sim}$

Votorantim

$\operatorname{sim}(70 \%)$

Cabreúva

$\operatorname{sim}$ (até $80 \%)$

Nota-se que na tabela 5, que quatro municípios incluem as APP's como áreas verdes, enquanto Votorantim considera $70 \%$ e Cabreúva até $80 \%$ dessas áreas protegidas nessa categoria.

Dreux (2004) cita que as áreas verdes urbanas destinadas à recreação têm origem na Inglaterra, tendo como referencial $28 \mathrm{~m}^{2}$ por habitante, desses, $16 \mathrm{~m}^{2}$ devem ter finalidades recreativa e desportiva. Quando avaliadas as áreas verdes como espaços de manutenção e oferta de serviços ambientais, salvo a questão da conectividade, sua localização não é de muita relevância. Quando essas áreas são vistas como espaços de lazer e recreação à população, sua declividade é de fundamental importância, visto que áreas com declividade acentuada são impróprias para uso da população. Desta forma, este item foi avaliado e notificado (Tabela 6) que apenas onze $(32,34 \%)$ dos municípios fazem menção a ele, exigindo em média que o percentual de declividade seja inferior a $30 \%$; os demais municípios (67,66\%) não fazem referência ao assunto.

É preocupante o fato observado de que seis, ou seja, 14,71\% (Araçariguama, Bofete, Iperó, Sarapuí e Ibiúna) dos municípios da UGRHI-10 ainda não possuírem legislação específica, que determine qual percentual de áreas verdes (Tabela 1). Os novos parcelamentos de solo devem adotar leis específicas para tanto. Estes consideram ainda as definições do, $\S 1^{\circ}$, do Art. $4^{\circ}$ da Lei federal n. 6.766/79, antes de sua revogação ocorrida em 1999.

As áreas verdes, dada sua importância social, ambiental e de saúde pública deveriam ter seu percentual definido através de um instrumento participativo, tal como um plano diretor, entretanto, dentre os vinte e um municípios pesquisados (61,77\%) (, Tabela 4) definiram seus percentuais por meio de leis ordinárias ou complementares, que podem ser aprovadas ou modificadas sem mecanismos participativos. Apenas 11 (32,25\%) (Tabela 4) deles aprovaram seus percentuais por 
meio de seus Planos Diretores e, somente pode ser modificado com rito participativo. Este fato não garantiu que estes municípios tivessem maiores porcentagens de áreas verdes. Neste contexto, as poucas informações, pesquisas e difusão do conhecimento relativo a essas áreas, como instrumento de preservação ambiental no ambiente urbano, ficaram prejudicadas.

Tabela 6: Modo como os municípios definem critérios relacionados à topografia para seleção das áreas verdes.

\section{Municípios}

Torre de Pedra

São Roque, Alumínio e Mairinque

Boituva e Itu

Alambari, Araçariguama, Bofete, Capela do Alto, Conchas, Jumirim, Pereiras, Piedade, Porangaba, Porto Feliz, Salto, Salto de Pirapora, Sarapuí, Sorocaba, Tatuí, Tietê, Iperó, Laranjal Paulista, Cerquilho e Vargem Grande Paulista

Ibiúna

Cesário Lange

Araçoiaba da Serra

Anhembi, Botucatu, Cabreúva, Quadra e Votorantim

\section{Considera declividade}

15 a $20 \%$

inferior a $15 \%$

não

não cita

sim exige inferior a $10 \%$

sim exige inferior a $20 \%$

sim exige inferior a $25 \%$

sim exige inferior a $30 \%$
O princípio político da participação está diretamente relacionado à legitimidade e à validade do plano diretor, fundamentado na necessária participação das populações nas decisões administrativas e nas discussões em que seus interesses estejam envolvidos, tais preceitos encontram amparo na Constituição Federal, em seus artigos 10, 11, 31, §3º $74, \S 2^{\circ}, 194$, VII, 206, 217, $\S 1^{\circ}$, entre outros (BRASIL, 1988). No Estatuto da Cidade, Lei Federal $n^{0}$ 10.257/2001, a democracia participativa está fixada como diretriz da gestão democrática e no seu artigo $2^{\circ}$ diz:

\footnotetext{
“II - gestão democrática por meio da participação da população e de associações representativas na formulação, execução e acompanhamento de planos, programas e projetos de desenvolvimento urbano [...]”, “XIII - audiência do Poder Público municipal e da população interessada [...]”; no artigo $40 \S 4^{\circ}$, inciso I, na “elaboração do plano diretor” (BRASIL, 2001).
} 
A aprovação pública dos planos diretores pressupõe a realização obrigatória de audiências e/ou de consultas públicas nas fases de discussão do projeto pelo poder executivo e pelo legislativo, anteriores à sua aprovação na Câmara Municipal, assim como se faz necessária a participação popular nos processos de revisão e alteração destes planos (BRASIL, 2001).

É notória a garantia participativa no processo de construção e alteração dos planos diretores, fato que não ocorre na formulação das Leis ordinárias e complementares de parcelamento de solo. Desta forma, a definição dos percentuais de áreas verdes encontra maior garantia de eficácia se definidos em plano diretor.

A Lei Federal $n^{\circ}$ 6.766/79 que rege o parcelamento do solo urbano, não fornece a definição de área verde e de lazer. No art. 180, VII da Constituição do Estado de São Paulo, as áreas verdes são citadas quanto ao seu destino dentro de loteamentos, o qual não pode ser modificado. Ainda, em relação à legislação, é comum em lei municipal de uso e ocupação do solo a definição de área verde idêntica a área de lazer (ARFELLI, 2004). Nessa mesma lei $\mathrm{n}^{\circ} 6.766 / 79$, em seu artigo $4^{\circ}$ cita que as áreas destinadas a espaços livres, dentre outras, serão proporcionais à densidade populacional. Tal preceito legal foi alterado pela Lei n. 9.785/99 e até tal ano, determinava o percentual fixo de $35 \%$ de espaços livres de uso público. Essa exigência, além de compensar e amenizar a degradação do ambiente valoriza o imóvel (SILVA, 2003).

A Resolução CONAMA (Conselho Nacional do Meio Ambiente) $n^{\circ} 369$ de 2006, em seu parágrafo primeiro, do artigo $8^{\circ}$, conceitua áreas verdes como:

\section{“[...] espaço de domínio público que desempenhe função ecológica, paisagística e recreativa, propiciando a melhoria da qualidade estética, funcional e ambiental da cidade, sendo dotado de vegetação e espaços livres de impermeabilização” [...] (BRASIL, 2001).}

\section{A Resolução 31 de 19 de Maio de 2009 da SMA-SP}

(Secretaria de Meio Ambiente do Estado de São Paulo), define que a área verde e sistema de lazer devem representar $20 \%$ da área do loteamento, sendo $70 \%$ desse valor destinado ao reflorestamento, até 30\% de jardins e até $30 \%$ de equipamentos urbanos, sendo que no local deverá ser assegurada a permeabilidade.

A Lei 10.257 de 10 de julho de 2001, que regulamenta os arts. 182 e 183 da Constituição Federal e estabelece diretrizes gerais da política urbana, em seu parágrafo único determina:

\section{“[...] Para todos os efeitos, esta Lei, denominada Estatuto da Cidade, estabelece normas de ordem pública e interesse social que regulam o uso da propriedade urbana em prol do bem coletivo, da segurança e do bem-estar dos cidadãos, bem como do equilíbrio ambiental” (Brasil, 2001).}

Neste contexto, as áreas verdes encaixam-se nessas funções.

Esses conflitos de definições, assim como o desrespeito da lei perante o destino dessas áreas é frequente e, muitas vezes, usados como desconhecidos no momento em que uma intervenção está sendo realizada em seu espaço. 
Benini e Martin (2009) descrevem uma série de conceitos ligados às áreas verdes, baseado tanto em autores quanto em legislações. As mesmas autoras citam subdivisões entre as áreas verdes, como características pontuais para cada uma, porém debatem que as informações encontram-se muito esparsas, sendo que o plano diretor dos municípios é que deve direcionar as ações a serem praticadas nessas áreas, inclusive sua abrangência.

Na análise de uma área verde deve-se considerar não somente seu espaço, mas também a quantidade, a diversidade, a condição e disposição da vegetação, o entorno, a acessibilidade, a porcentagem de área permeável, a função social e os equipamentos de recreação e lazer (NUCCI, 2008). A grande dificuldade da qualificação desses itens encontra-se na valorização dos benefícios por elas trazidos, tanto valores ambientais, estéticos, sociais ou financeiros (CAPORUSSO; MATIAS, 2008).

\section{CONSIDERAÇÕES FINAIS}

O Plano diretor é um instrumento básico, tendo como principal função o ordenamento da cidade. É dotado de mecanismos que possibilitam ser participativo e pode ser uma excelente ferramenta democrática. As outras legislações mencionadas anteriormente, como o Estatuto da Cidade e a Lei do Parcelamento do solo urbano, somente reforçam e subsidiam sua função. Por isso, essas ferramentas devem ser utilizadas conjuntamente para explorar da melhor forma o tema áreas verdes, as quais são citadas, nem sempre com essa denominação, nas entrelinhas dos documentos, aparecendo muitas vezes como áreas livres, de recreio ou mesmo de lazer.

Dentro da proposta do Plano Diretor e das legislações que abrangem o tema áreas verdes, visando ampliar e organizar a situação delas no interior das cidades faz-se necessário um estudo mais abrangente, tendo em vista a importância desses espaços em centros urbanos, contribuindo com a função ecológica, social, estética, educativa e psicológica, como locais que aumentam a qualidade de vida da população do entorno e ofertam uma série de serviços ambientais a ela.

Embora a legislação federal remeta ao município a autonomia para legislar e ditar normas acerca do uso e parcelamento do solo, é esperado que ocorra semelhança entre essas, entretanto, na Unidade de Gerenciamento de Recursos Hídricos -10 foi observado que a questão relativa às áreas verdes de novos parcelamentos de solo apresenta uma heterogeneidade nas formas com que são tratadas, não havendo um critério lógico, científico ou racional que estabeleça a forma de cálculo do percentual destas áreas e nas glebas a serem parceladas. Há variação entre 5\% e $20 \%$ de áreas verdes, dependendo do município, com predominância para o percentual de $10 \%$ da porção que deve ser destinado. Este valor não é explicado e não tem referencial na literatura, sendo que possivelmente este índice tenha origem na legislação federal que determinava (antes de 1999), que o percentual mínimo deveria ser de 35\% da gleba destinada ao sistema viário, áreas verdes e institucionais. Em geral, dependendo de diversos fatores topográficos, físicos e ambientais, na prática, excluindo as áreas do sistema viário (de porcentagem variável) e 5\% de áreas institucionais, havia disponibilidade em média de $10 \%$ de território para destinar a área verde. É provável que tenha sido esta a origem deste percentual, porém, as alterações na legislação federal que transmitiram ao

Daniela Gerdenits et al. 
município o poder de decisão nesta matéria, foram explícitas ao dizer que o cálculo destas áreas deve considerar a densidade populacional. Para isso, é necessário saber qual é o percentual ideal de área verde por habitante, questão que também não encontra respaldo suficiente na literatura.

É notório que não há um consenso, nem dados suficientes, sobre qual é a área ideal por habitante para poder estabelecer uma relação entre o percentual de área verde e densidade populacional.

Urge a realização de pesquisas que determinem, diante da realidade brasileira, qual é o valor adequado de área verde por habitante, necessário para garantir uma qualidade de vida sustentável à população.

Esse importante instrumento de preservação de espaços públicos, que podem servir para oferta de serviços ambientais nos meios urbanos, não conta com base sólida de pesquisa que possibilite sustentar qual o percentual adequado para sua implantação. Esta questão abre caminho para que os interesses comerciais dos empresários do setor imobiliário exerçam forte "lobby” nos municípios, em prol de percentuais cada vez menores destas áreas.

É necessário que os diversos segmentos da sociedade, que trabalhem com planejamento urbano, meios invistam em pesquisas, acerca da importância e percentuais mínimos destas áreas no meio urbano, desta forma haverá subsídio para definir qual valor de área verde de um loteamento é o mais adequado para garantir os serviços pelos quais ela foi criada, podendo gerar mecanismos que possibilitem relacionar a porcentagem destas áreas com a densidade populacional, fato previsto em lei.

\section{REFERÊNCIAS BIBLIOGRÁFICAS}

ARFELLI, A. C.. Áreas verdes e de lazer: considerações para sua compreensão e definição na atividade de parcelamento do solo. Revista de Direito Ambiental. São Paulo, v. 9, n. 33, p. 37, jan/mar 2004.

BENINI, S. M.; MARTIN, E. S. Decifrando as áreas verdes públicas. Revista Formação, n.17, volume 2 - p. 63-80, 2009. Disponível em: <http://revista.fct.unesp.br/index.php/formacao/article/viewFile/455/489>. Acesso em: 05/01/12.

BRASIL. Lei Federal nº 6.766, de 19 de dezembro de 1979.

BRASIL. Constituição da República Federativa do Brasil, de 05 de outubro de 1988. Brasília, DF, Senado, 1988.

BRASIL. Resolução Conjunta IBAMA/SMA n. 02, de 12 de maio de 1994.

BRASIL. Lei Federal nº 10.257, de 10 de julho de 2001.

CAPORUSSO, D.; MATIAS, L. F. Áreas verdes urbanas: avaliação e proposta conceitual. $1^{\circ}$ SIMPGEO/SP, Rio Claro, 2008. Disponível em: <www.rc.unesp.br/igce/simpgeo/71-87danubia.pdf. Acesso em 10/08/11>. Acesso em 15/12/11. 
DREUX, V. P. Uma avaliação da legislação urbanística na provisão de equipamentos urbanos, serviços e áreas de lazer em conjuntos habitacionais. Dissertação de Mestrado, 181 pg., UFRGS, Porto Alegre, 2004. FÁVERO, O. A. Paisagem e sustentabilidade na Bacia Hidrográfica do Rio Sorocaba (SP). Tese de Doutorado, 330 pg., USP, São Paulo, 2007.

GUZZO, P. Áreas verdes. Disponível em:

< http://educar.sc.usp.br/biologia/prociencias/areasverdes.html>. Acesso em 15/04/11.

HENKE-OLIVEIRA, C. Planejamento ambiental na cidade de São Carlos (SP) com ênfase nas áreas públicas e áreas verdes: diagnóstico e propostas. Dissertação de Mestrado. Universidade Federal de São Carlos, São Carlos-SP, 1996.

INSTITUTO Brasileiro de Geografia e Estatística. Censo Demográfico 2010. Brasília: IBGE, 2010. Disponível em: $<$ http://www.ibge.br $>$. Acessado em 15/01/12.

LIMA, A. M. L. P. et al. Problemas de utilização na conceituação de termos como espaços livres, áreas verdes e correlatos. In: CONGRESSO BRASILEIRO DE ARBORIZAÇÃO URBANA, 2, 1994. São Luis/MA. Anais... São Luis: Imprensa EMATER/MA, 1994. p. 539 . 553.

LOBODA, C. R.; DE ANGELIS, B. L. D. Áreas verdes públicas urbanas: conceitos, usos e funções. Ambiência - Revista do Centro de Ciências Agrárias e Ambientais, Guarapuava, PR v.1 n.1 p. 125-139 jan./jun. 2005.

MANTOVI, V. Áreas verdes: uma percepção paisagística do refugio biológico Bela Vista no meio urbano de Foz do Iguaçu. 2006. Monografia. Especialista no Curso de Pós-Graduação em Análise Ambiental e Regional em Geografia. Colegiado do curso de Geografia - Centro de Ciências Humanas Educação e Letras Universidade Estadual do Oeste do Paraná. Marechal Candido Rondon-PR.

NUCCI, J. C. Análise sistêmica do ambiente urbano, adensamento e qualidade ambiental. Revista PUC SP Ciências Biológicas e do Ambiente, São Paulo, v. 1, n. 1, p. 73-88, 1999.

NUCCI, J. C. Qualidade ambiental e adensamento urbano: um estudo de ecologia e planejamento da paisagem aplicado ao distrito de Santa Cecília (MSP) / João Carlos Nucci. 2a ed. - Curitiba: O Autor, 2008. 150 p. Disponível no endereço: <http://www.geografia.ufpr.br/laboratorios/labs. Acesso em 10/08/11>. Acesso em 15/08/11.

PINTO, V. C. Regime Jurídico do Plano Diretor. In: Temas de direito urbanístico 3. Ministério público do Estado de São Paulo. São Paulo: Imprensa Oficial, 2001. p. 417. 
RANGEL, H. M. V.; RIBEIRO, H. B. A impossibilidade de desafetação de áreas verdes incorporadas ao domínio municipal por força de aprovações de loteamentos. In: Anais do XIX Encontro Nacional do CONPEDI. Fortaleza - CE 09 a 12 de Junho de 2010. Disponível em:

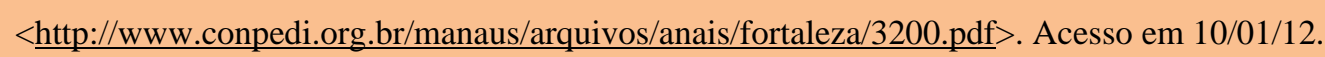

SÃO PAULO. Lei nº 7.663, de 30 de dezembro de 1991.

SÃO PAULO. Resolução CONAMA n 369, de 28 de março de 2006.

SÃO PAULO. Resolução SMA-SP 31, de 19 de Maio de 2009.

SILVA, M. F. A desafafetação de áreas verdes advindas de aprovação de loteamentos perante a tutela ambiental. Jus Navigandi, Teresina, ano 7, n. 113, 25 out. 2003. Disponível em: $<$ http://jus2.uol.com.br/doutrina/texto.asp?id=4208>. Acesso em: 18/08/08. 